\title{
Brief Discussion on Application of Guided Boring Non-excavation Technology in Repair of Sewage Pipes
}

\author{
Mei-Di SHAN ${ }^{1, a, *}$, Feng ZHOU ${ }^{2, b}$ \\ ${ }^{1}$ China Tobacco Zhejiang Industrial Co., Ltd \\ ${ }^{2}$ China Tobacco Zhejiang Industrial Co., Ltd \\ a979248535@qq.com, bzfzhou@zjtobacco.com \\ * Corresponding author
}

Keywords: Guided Boring Technology, Non-excavation, Repair of Sewage Pipe, PE Pipe.

\begin{abstract}
The buried sewage pipes of a large industrial plant area is deformed and blocked due to soil compression and other causes. The guided boring non-excavation technology is used to safely and efficiently complete repair for sewage pipes. Based on engineering practice, this paper discussed the working principle, advancement, construction process flow, implementation and quality of works for guided boring non-excavation technology, to provide reference for other repair works of buried sewage pipes.
\end{abstract}

\section{Introduction}

The guided boring non-excavation technology is first proposed by Utilx USA in 1985, rapidly develops soon after worldwide with its unique technical advantages and widely applies to the pipe laying of power, natural gas and gas and so on ${ }^{[1]}$. With the continuous development of urban economy and strengthening of environmental protection awareness, there are more and more challenges during works of municipal sewage pipes, e.g. crossing road, river and other obstacles, complex working conditions, pipe network, external pressure on environmental protection requirements, etc. To solve these problems, the successful experience of guided boring technology in laying of communication and power lines is introduced in some sewage pipe works that the drainage pipes are laid without excavation. Compared to manual excavation and mechanical excavation with severe destruction and high risk, the technical advantages of the non-excavation technology are gradually obvious. This paper combined the repair works of buried sewage pipes in large industrial plant area to discuss the guided boring non-excavation technology and its application on the repair works of sewage pipes so as to provide a new option for repair of buried sewage pipes.

\section{Introduction to Guided Non-excavation Technology}

\section{Concept}

The guided boring non-excavation technology is a construction technology that utilizes guided surveying and control technologies for laying of water, gas, sewage, telecommunication cables and other utilities pipes with no trench excavation and minimum damage to stratum structure. Such technology mainly includes guided boring, directional boring, micro tunnel boring, impact moling, rammed pipe laying technologies ${ }^{[2]}$. As one of the non-excavation technologies, the guided boring technology is characterized by its high construction accuracy and wide range of application and is a rapidly developed special construction method ${ }^{[3]}$.

\section{Advancement}

The guided boring pipe laying technology is the most advanced technology for non-excavation pipe laying technology (for medium and small pipes) home and aboard. Compared to the manual excavation with longer duration, higher strength of workers, higher safety risk and the mechanical excavation of severer destruction, more safety problems, the guided boring non-excavation 
technology has its own advantages mainly including ${ }^{[4,5,6]}$ :

(1) Direction-controlled. The advanced guided surveying and control system can detect the position, depth and horizontal inclination, discover and correct any deviation at any time during boring.

(2) Well applicable. It can be used for the underground pipework when traditional excavation method cannot be used or the conditions on site are very complex, e.g. crossing river, highway, historic and cultural site, etc.

(3) Economical. The duration is short, pipes can be paved in one operation for long distance, and the comprehensive cost is low.

(4) Environmental-friendly. The squeezing boring avoids the partly reduction of bearing capacity when the roadbase is in the river, the destructive power on stratum structure is relatively low, normal traffic conditions and safe use of underground pipes are guaranteed.

(5) Safe. It is mechanically operated with lower construction risk.

\section{Working Principle}

The technology is based on the working principle that, guided by the navigator, the bore bit travels along the design path to make the boring path coincide with the design path. After boring, the hole is back-pulled and reamed and then pipes are paved at design positions (as shown in Fig. 1$)^{[7]}$.

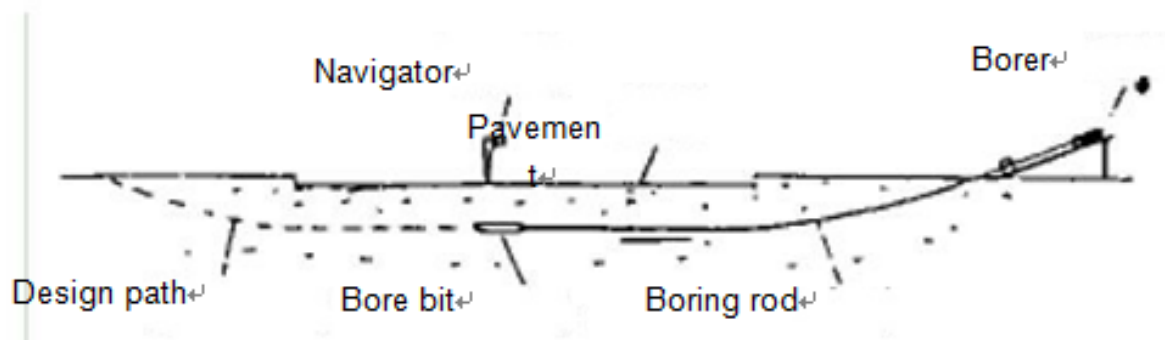

(a)

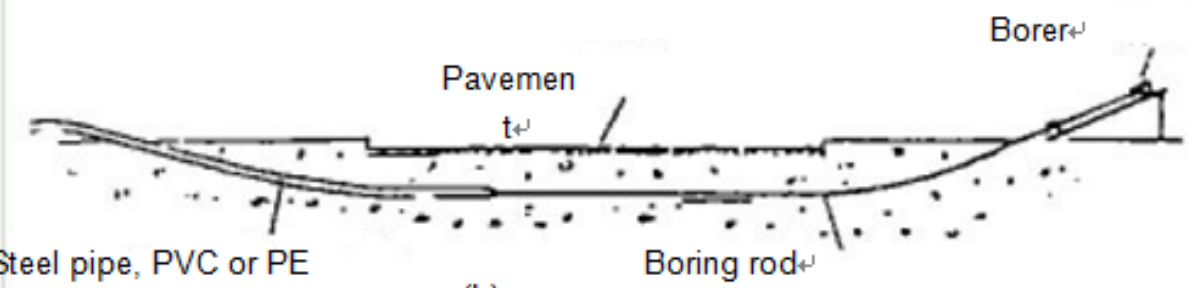

pipe

(b)

(a) Guided Boring; (b) Back-pulling of Pipe

Fig.1 Working Principle of Guided Boring Non-excavation Technology

\section{Application of Guided Boring Non-excavation Technology in Repair Works of Sewage Pipes}

\section{Project Profile}

A large industrial plant area covers a land area of approximately $1000 \mathrm{mu}$, mainly including workshops, office, power center and other auxiliary houses, with GFA of 300,000m2, the green space in the plant area of $180,000 \mathrm{~m} 2$ and the road area of $200,000 \mathrm{~m} 2$. Various power lines are laid in the green belt, in which the sewage pipes are total $8600 \mathrm{~m}$ long with diameter of about $300 \mathrm{~mm}$, and the buried depth elevation is $3 \mathrm{~m}$, with $-4 \mathrm{~m}$ at deepest. Some fire-fighting pipes and gas pipes are laid above these pipes.

There are 5 sewage shafts to the south of the power center in the plant area with total length of approximately 140m, among which the lowest sewage Shaft $5 \#$ cannot normally discharge sewage. Based on field survey and analysis, the construction risk is very high if it is excessively excavated, 
the safety of original pipe network, roads and power center nearby cannot be guaranteed, moreover, the problem cannot be solved by caisson excavation partly. Therefore, the guided boring non-excavation technology is used to repair the sewage pipe. The non-excavation boring process starts from Shaft 1\# to 5\#, 3.5m deep (arranged at deepest) and the plan of repair works is shown in Fig.2.

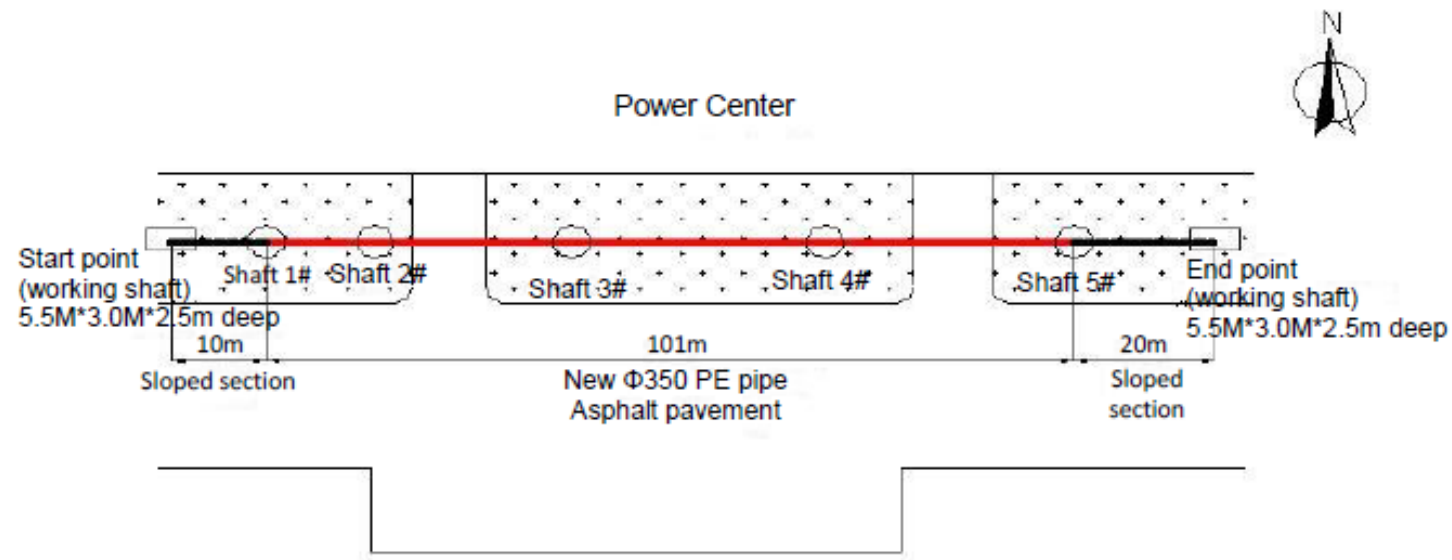

Fig.2 Plan of Repair Works of Sewage Pipes in Large Plant Area

\section{Process Flow and Implementation}

The guided borer (GD380 directional borer) is placed at the entrance point (10m on the west of Shaft $1 \#)$, drilled to exit point $(20 \mathrm{~m}$ on the east of Shaft $5 \#)$ to ream the hole to proper diameter, then the pipe is back-pulled to position from the end point. The detailed process flow is shown in Fig.3.

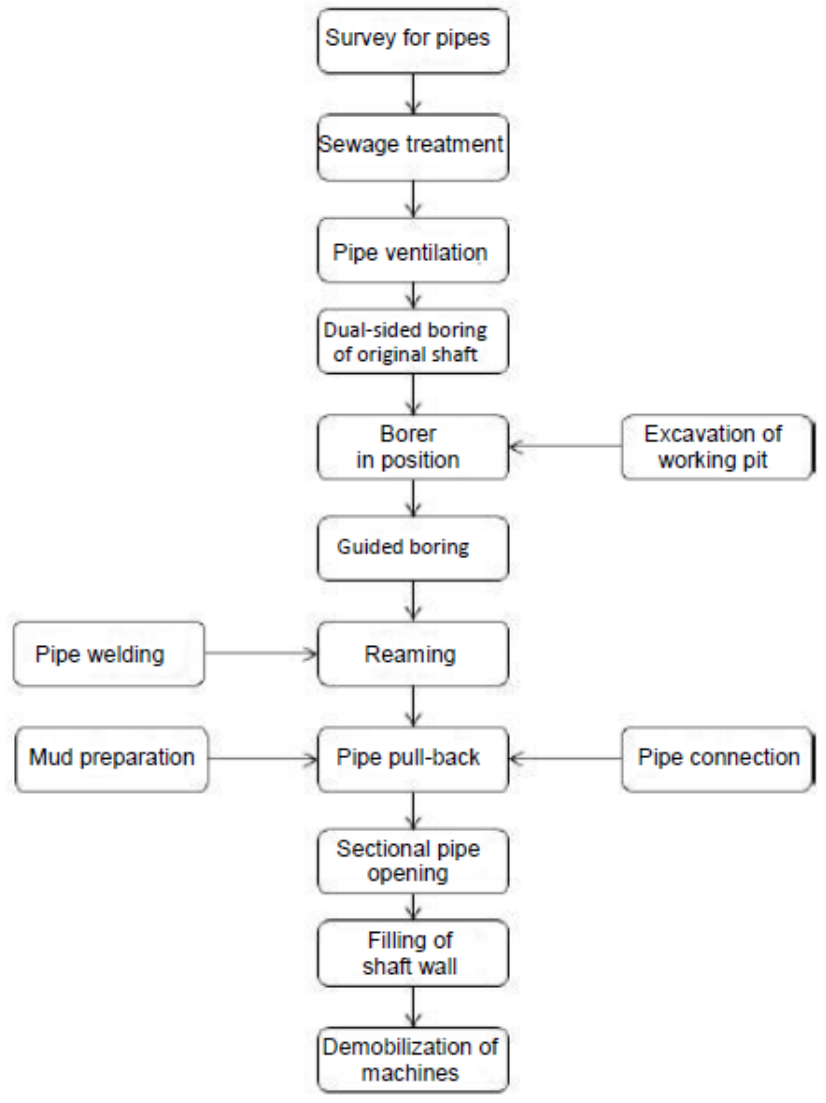

Fig.3 Construction Process Flow 


\section{Implementation and Quality Control Points during Works}

According to national regulations and standards, many field survey and theoretical calculation were carried out for important sequence and difficulties during work, and detailed construction technological program was made. The main steps and quality control points of the technological program are as below:

(1) Survey for original pipes on site: when the guided boring non-excavation technology is surely adopted for the repair of sewage pipes in the works, the project department immediately organizes relevant technical personnel to survey and locate original pipes on site, take accurate records and make a detailed repair program based on these information.

(2) Treatment of original pipes on site: after original pipes surveying, 10 sewage pumps (7KW) are used to drain the sewage in pipes and ensure that there is no sewage in Shaft 1\# and 5\#.

(3) Pipe ventilation: after the sewage in original pipes are drained, the shaft is protected by enclosure and watched by special personnel for ventilation after draining.

(4) Dual-sided boring of original shaft: after ventilation for a period, relevant personnel are organized for dual-sided boring of the shaft based on preliminary field survey and the calculated direction and elevation of boring.

(5) Excavation of working pit: 2 working pits are excavated, including a $5.5 \mathrm{~m} * 3.0 \mathrm{~m} * 2.5 \mathrm{~m}$ pit at the start point $10 \mathrm{~m}$ on the west of Shaft $1 \#$ and a $5.5 \mathrm{~m} * 3.0 \mathrm{~m} * 2.5 \mathrm{~m}$ pit at the end point $20 \mathrm{~m}$ on the right of Shaft $5 \#$.

(6) Guided boring: the equipment system is first commissioned to ensure that it can normally work, with the electromagnetic wave from the detecting rod on the guiding bore bit and the receiving function of the directional measuring instrument (eclipse navigator in the works), the depth, horizontal angle and tool angle are measured and controlled in an organic manner. Here is the pipe laying program for the works. The original pipe is used as sloped section for the 10 pipe from start point to Shaft $1 \#$ and the $20 \mathrm{~m}$ pipe from Shaft $5 \#$ to end point, the single-hole PE pipe of $101 \mathrm{~m}$ long, diameter $350 \mathrm{~mm}$ is added between Shaft 1\# and 5\#. During guided boring, the guided boring measuring and control instrument and signal transmitter shall be calibrated every time before work to control the measuring error below $+5 \% \mathrm{D}$ ( $\mathrm{D}$ for depth of bore bit). The bit is stopped every $3 \mathrm{~m}$ for measurement and recording, and every $1 \mathrm{~m}$ at start point, end point and key points near original pipe to guarantee accuracy and safety of pipe laying. The excavator, pulley block and lifting jack are used to pull back the boring rod or reduce the back-reaming speed in case of wedging of drill tool, the reamer of smaller diameter is used for back-reaming if necessary.

(7) Reaming: the squeezed reaming is used in the works, the streamlined reamer is used for staged reaming while the ground bearing capacity is not affected, the diameter and times of reaming change with the torque of boring diameter, back-pulling force and stratum conditions. The mix proportion of mud is adjusted based on soil conditions during reaming for better effect, when there is hidden problem of collapse or clamping during back-reaming, the bit of the next stage shall be stopped stop to adjust the method statement. The hole wall is reinforced by injecting mud during works and the mud shall be mixed depending on actual geological conditions on site.

(8) Pipe welding: the PE pipes in the works are hot-melt connected that the hot-melt welding regulations are strictly observed during work so that the works is completed in a safe and smooth manner.

(9) Back-pulling of pipes: the pipe is back-pulled after the hole is reamed to design diameter. Due to the uniqueness of the construction technology, the back-pulling process of pipes shall be executed in a rapid way to prevent reduction in pipe diameter, and add friction force on pipe wall that might bring about unnecessary difficulty to the works.

(10) Filling of shaft wall: as the shaft is dual-bored before laying, there is gap between pipe and shaft wall after back-pulling, hence, it is filled with concrete of certain mortar content depending on the soil conditions of the works, such detailed work shall not be ignored. 


\section{Conclusion}

In addition to the inherent advancement, the guided boring non-excavation technology also fills up the deficiency of environmental pollution by traditional excavation works, which is compliant with the concept of green and environmental protection worldwide. Therefore, it has been more and more widely used. The successful application of guided boring non-excavation technology in the repair works of underground sewage pipes for large industrial plant area, directs a new way for the repair of sewage pipes. With the increase of people's environmental protection awareness, enhancement of modern urban construction and management, the advancement and advantages of the guided boring non-excavation technology will definitely be widely applied and promoted with its uniqueness.

\section{References}

[1] Zhang Yachun, Li Jiwu. Guided Trenchless Pipeline Installation Technique Using Guided Boring [J]. Exploration Engineering (Rock \& Soil Drilling and Tunneling), 1996, 06:16-18.

[2] Che Yangang. Abstract of Guiding Drilling Technic [J]. Municipal Engineering Technology, 2002, 04:41-46.

[3] Dou Bin, Jiang Guosheng. Development Situation and Prospect of Trenchless Technology In Our Country [J]. Geotechnical Engineering World, 2001, 4 (4): 47-48.

[4] Zhang Jian. Application of non-excavation technology in municipal road works [J]. Cities and Towns Construction in Guangxi, 2008, 10: 65-66.

[5] Zhang Qijun, Zhang Zhonghai. General Sitations of Horizontal Directional Drills and Discussion on Their Market Perspectives [J]. Construction Machinery and Equipment, 2004, 6: 26-28.

[6] Che Yangang, Zhang Guanglie, Chen Zhiyi, Yuan Mingxin. Unexcavated Technology with Guided Boring for Pipe Engineering [J]. Construction Mechanization, 2002, 2: 27-31.

[7] Fu Haian. Horizontal Directional Drilling Technology in the Application of Sewage Pipe Laying [D]. Xi an University of Architecture and Technology, 2013. 